Anthony Bowlby, Sir J. Rose Bradford, Sir H. Bryan Donkin, Mr. G. H. Makins, Dr. Seymour J. Sharkey, and Mr. Charters J. Symonds. This Advisory Committee is appointed in accordance with the recommendation of the Royal Commission on Vivisection.

Aт a Comitia held on Monday last Sir Thomas Barlow was re-elected President of the Royal College of Physicians of London.

Dr. Philip Frank, who died on Monday last at his London residence, at the age of 82 , was for very many years a wellknown consultant physician both in London and at Cannes.

\section{THE NATURE OF TEA INFUSIONS.}

\section{By Henry L. Shith, B.Sc., F.I.C.}

IN January and December of 1911 two papers appeared in THE LANCET on this subject. ${ }^{1}$ These papers explained that in the course of an investigation into the nature of tea infusions precipitates were obtained by (a) adding acid and (b) saturating with ammonium sulphate. On analysis of these precipitates very constant ratios of caffeine to tannin 1:3 were obtained. Caffeine has formula $\mathrm{C}_{5} \mathrm{H}_{10} \mathrm{~N}_{4} \mathrm{O}_{2}=194$; the tannin is supposed to be identical with quercitannic acid, the formula adopted being $\mathrm{C}_{25} \mathrm{H}_{26} \mathrm{O}_{15}=602$. If the precipitate contains caffeine and tannin in equimolecular proportions the ratio would be therefore practically 1:3. However, the formula given in the latest edition of Allen's "Commercial Organic Analysis" is $\mathrm{C}_{19} \mathrm{H}_{16} \mathrm{O}_{10}=404$, while Etti gives $\mathrm{C}_{1} \mathrm{H}_{10} \mathrm{O}_{9}=368$, which would give ratios a little over or under $1: 2$. The reports in THE LANCET state that tea infusions are essentially solutions of caffeine tannate in an alkaline medium, that they are always alkaline, and that good teas do not precipitate gelatin, as the caffeine is combined with the tannin, and unless there is excess of tannin present it has no coagulating power on proteins. This work and the conclusions drawn seemed of sufficient interest for furt her investigation.

In investigating a number of teas I have found every tea infusion to give an acid reaction with litmus paper, unless the water used was distinctly alkaline. Also unless sodium carbonate or other alkali be present, all tea infusions examined precipitated gelatin. Even a water containing calcium bicarbonate and alkaline to methyl orange made an infusion that precipitated gelatin. If a little infusion be added to a large excess of gelatin, the precipitate is not evident at first owing to the viscosity of the gelatin, but in presence of a small amount of gelatin the precipitate was formed.

It is well known that caffeine citrate is hydrolysed in aqueous solution, the alkaloid and citric acid being in the free state. The same might be expected of caffeine tannate. This is shown to be so by the following experiment. 100 c.c. of tea infusion containing 0.054 gramme caffeine was extracted with chloroform. On evaporating the chloroform 0.067 gramme of impure caffeine was obtained. On purifying this by means of lead acetate, followed by sodium phosphate to remove excess of lead, and extracting with chloroform 0.052 gramme caffeine was obtained.

A hot tea infusion is clear; on cooling most become turbid. On extracting the turbid solution with chloroform all the caffeine is obtained, and the residual liquid becomes practically clear. The turbid solution deposits a little precipitate on long standing, and more may be obtained on long centrifugalisation. This precipitate contains both caffeine and tannin, but insufficient was obtained for quantitative examination. Some precipitates were obtained in the manner described in THE LANCET report of 1911 and analysed. The method of e:timating the tannin descrined is open to criticism, as it depends on the assumption that the alcohol and benzene dissolve nothing but caffeine and tannin, the residue after removal of caffeine being taken as tannin.

In the following experiments Procter's modification of the

1 The LaNCeT, Jan. 7th (p. 46) and Dec. 2nd (p. 1573), 1911. permanganate method was used. The precipitate was dissolved in alcohol, added to water, boiled to remove alcohol, and macle up to a definite volume. On cooling this was usually turbid. It was shaken up, an aliquot portion added to a littile dilute sodium carbonate, and this at once added to the acid indigo solution and titrated. Another aliquot portion was detannated by gelatin in the usual way and filtered. A portion containing the same amount of the original solution was again titratecl, the difference in the titrations giving the permanganate equivalent to the tannin. The tannin was calculated as quercitannic acid, the reducing power of which is practically identical with oxalic acid. Three teas were used :-

1. Ceylon containing caffeine, $3 \cdot 18 \% \ldots$ Tamnin, $14 \cdot 10 \% \ldots 1.4 \cdot 43$ ratio. $\begin{array}{llllllll}2 . & \text { Indian } \quad, \quad 3.86 \% & \ldots & , & 14.35 \% & \ldots & 1: 3.71,\end{array}$

3. Assam $\quad$ " $\quad 3.08 \% \ldots \quad, \quad 13 \cdot 73 \% \ldots 1: 4 \cdot 45$,

The infusions were of 5 grammes in 250 c.c. for 5 minutes.

Results.

A. Precipitated with dilute sulphuric acid and ammonium sulphate.

\begin{tabular}{|c|c|c|}
\hline a ... & $\begin{array}{l}\text { Caffeine in ppt. } \\
\ldots \quad 0 \cdot 1125 \text { grm. }\end{array}$ & $\begin{array}{l}\text { Tannin. } \\
0.316 \text { grm. }\end{array}$ \\
\hline Indian ... & $\begin{array}{lllll}\ldots & 0.0975 & , & \ldots .\end{array}$ & 0.263, \\
\hline
\end{tabular}

B. Precipitated with dilute sulphuric acid.

$\begin{array}{llllllllllll}\text { Ceylon } & \ldots & \ldots & \ldots & 0.050 & \mathrm{grm} . & \ldots . . & 0.269 & \mathrm{grm} & \ldots \ldots & 1: 5 \cdot 38 \\ \text { Indian } & \ldots & \ldots & \ldots & 0.028 & , & \ldots \ldots . & 0.151 & , & \ldots . . & 1: 5 \cdot 39 \\ \text { Assam } & \ldots & \ldots & \ldots & 0.073 & , & \ldots \ldots . & 0.325 & , & \ldots \ldots . & 1: 4 \cdot 45\end{array}$

The filtrates from these were saturated with ammonium sulphate and a further precipitate obtained. The precipitates contained :-

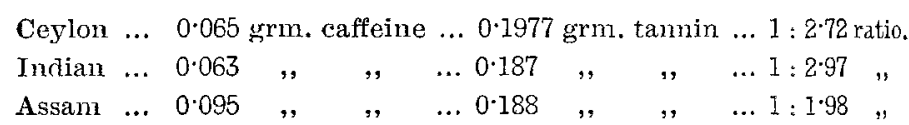

In 100 c.c. of the filtrate from these was found:-

Ceylon ... $0.039 \mathrm{grm}$. caffeine ... $0.076 \mathrm{grm}$. tannin. ... 1:2.62 ratio. Indian $\ldots .0 .025 \quad, \quad, \quad \ldots 0.071 \quad, \quad, \quad \ldots 1: 2 \cdot 84 \quad$,

From these results it is evident that the precipitates do not indicate the nature of the association of caffeine and tannin in the infusion. Saturation with ammonium sulphate precipitates caffeine from its pure aqueous solution. In the hot tea infusion it may be concluded that caffeine and tannin occur considerably hydrolysed and in the free state. On cooling a little substance is precipitated containing caffeine and tannin closely associated.

On adding acid it is well known that anhydrides of the tannin are formed which are insoluble in water. Tannin precipitates many alkaloids, but does not completely precipitate caffeine. Some of the precipitate was dried in vacuo over strong sulphuric acid. It contained $14 \cdot 1$ per cent. caffeine and 36.9 per cent. tannin. On shaking up with water and chloroform all the caffeine was obtained in the chloroformic extract. On treating the dried precipitate with dry chloroform 0.91 to 0.98 per cent. caffeine only was obtained. The dried powder must, therefore, contain the caffeine closely associated or combined with tannin. It does not appear to be a pure substance. Ethyl acetate dissolves ont a reddish-brown, non-crystalline substance. Alcohol dissolves most of the residue and yields on evaporation a dark brown, non-crystalline residue. Both contained caffeine and tannin. Whatever combination takes place between the caffeine and tannin in these precipitates they do not appear to be a pure or definite caffeine tannate; they vary with the tea and the method of precipitation.

The ratios given are not necessarily comparable with those given in the papers of 1911, the method of analysis being different. However, they are comparable among themselves, and show that the substance precipitated varies in composition and that neither all the caffeine nor all the tannin is precipitated from tea by ammonium sulphate.

While the nature and molecular formula of the tannin of tea is so uncertain, it is premature to form any definite conclusions as to the nature of these precipitates. Further work is being done which, it is hoped, will help to solve the question. 